\title{
Influence of insertion/deletion and transcriptional activity of Alu-elements on human longevity
}

\author{
V. Erdman*, D. Karimov, T. Nasibullin, I. Tuktarova, O. Mustafina \\ Institute of Biochemistry and Genetics, Ufa Federal Innovation Center, RAS, Ufa, Russia \\ *e-mail:danivera@mail.ru
}

Key words: human longevity, Alu-element, insertion/deletion polymorphism, transcriptional activity

Motivation and Aim: It is hypothesized that genome instability can affect the lifespan [1]. Alu-insertions are one of the causes of such instability. This element can contain regulatory sites, such as silencers, and therefore influence transcriptional activity (TA) of genes [2]. Our aim was to search association of longevity with insertion/deletion and TA of Aluelements in some genes, whose protein products involved potentially in age-associated processes - apoptosis, immune reaction, intra- and extracellular signaling and others. Methods and Algorithms: Total group was formed of 2000 unrelated individuals aged from 21 to 113 years, ethnic Tatars (residents of Republic of Bashkortostan, Russia). PLAT, COL13A1, ACE, LAMA2, EVI5, STK38L, PKHD1L1, HECW1, SOX5, CDK11A, NOTCH2, PTPRO, SEMA6A and TEAD1 genes were selected for the analysis of Aluinsertion/deletion polymorphism and TA. DNA was isolated from lymphocytes of peripheral venous blood by phenol-chloroform method. Alu-polymorphism was detected with PCR. Total RNA was extracted from peripheral blood leukocytes using TRIzol reagent following manufacturer's instructions. First strand cDNA was synthesized from RNA template using reverse transcription PCR. TA of Alu-elements in selected genes was detected by RT-PCR. Logistic regression analysis was used to assess age dynamics of genotype and allele frequency. $\Delta \Delta \mathrm{C}_{\mathrm{t}}$-method was applied to analyze gene TA.

Results: It was found that the chances to achieve longevity were increased in females with $C O L 13 A 1 * \mathrm{D} / * \mathrm{D}, L A M A 2 * \mathrm{I} / * \mathrm{D}, T E A D 1^{*} \mathrm{I} /{ }^{*} \mathrm{I}, P K H D 1 L 1 * \mathrm{I} / * \mathrm{I}$ genotypes, in males with $P K H D 1 L 1 * \mathrm{I} / * \mathrm{D}$ genotype, and were decreased in females with $A C E^{*} \mathrm{D} /{ }^{*} \mathrm{D}$ and $L A M A 2^{*} \mathrm{D} / * \mathrm{D}$ genotypes. Carriers of $C D H 4 * \mathrm{D} / * \mathrm{D}$ genotype had higher chances to become centenarians. TA of COL13A1 gene progressively decreased during aging, but peaked up again at very old ages. Expression level of $L A M A 2$ gene was higher among carriers of $L A M A 2 * \mathrm{D}$ allele compared to individuals with $L A M A 2 *$ I allele.

Conclusion: Alu-polymorphism of COL13A1 (Ya5ac1986), ACE (Ya5ACE), LAMA2 (Ya5-MLS19), PKHD1L1 (Yb8AC702), CDH4 (Yb8NBC516) and TEAD1 (Ya5ac2013) genes is likely associated with chances of longevity. Alu-polymorphism of LAMA2 gene influences its TA among long-livers. It can be suggested that Alu(I/D) polymorphism of selected genes can be influence on the development of a number of age-dependent pathologies through a change in the gene expression level.

Acknowledgements: Supported by RFBR (No. 17-44-020735).

\section{References}

1. Mustafina O.E. (2012) The possible roles of human Alu elements in aging. Papers of the conference on genetics of aging and longevity. Frontiers E-books: 129.

2. Cardelli M., Marchegiani F. (2013) Good, bad, mobile elements: genome's most successful "parasites" as emerging players in cell and organismal aging. Current Pharmaceutical Design. 19(9):1739-1752. 